\title{
Influenza and pneumococcal vaccination in long term care facilities in two regions of Quebec
}

Philippe De Wals mD phD, Michel Carbonneau msc, Hélène Payette PhD, Théophile Niyonsenga PhD

P DE WALS, M CARBONNEAU, H PAYETTE, T NIYONSENGA. Influenza and pneumococcal vaccination in long term care facilities in two regions of Quebec. Can J Infect Dis 1996;7(5):296-300.

OBJECTIVES: To evaluate the use of influenza and pneumococcal vaccines in long term care facilities. DESIGN: Cross-sectional survey in a random sample of 30 facilities in two regions of Quebec. Information was collected from the general manager or the chief of nursing, all consultant physicians and a random sample of 20 residents in each facility.

RESULTS: Twenty-nine centres agreed to participate. The mean influenza vaccination rate was $70 \%$, and was not influenced by differences in the types of facilities or the organization of the programs for immunization. The main obstacle to influenza vaccination reported by physicians was nonacceptance by a significant proportion of residents. Of the residents who did not initially request influenza vaccine, only $64 \%$ accepted vaccination when it was offered. The vast majority of residents were satisfied with the information they had received and the respect shown for their freedom of choice. Forty per cent of residents were unfit to provide a valid consent and the vaccination rate was $76 \%$ in this group. Only one-third of the physicians regularly obtained authorization from a relative or the legal guardian before prescribing vaccination for incompetent residents. None of the facilities studied had an effective program for pneumococcal vaccination, only $43 \%$ of the physicians reported any use of pneumococcal vaccine and $98 \%$ of residents had never heard of the vaccine.

CONCLUSIONS: The national objective of $95 \%$ coverage with influenza vaccine will be difficult to achieve in long term care facilities, mainly because a minority of residents are not likely to be convinced of the benefit of immunization. Much remains to be done to promote and administer pneumococcal vaccine in this setting.

Key Words: Immunization, Influenza, Nursing homes, Pneumococcus, Quebec, Vaccine

\section{Vaccination contre l'influenza et l'infection pneumococcique dans des établissements de soins prolongés de deux régions du Québec}

OBJECTIFS : Évaluer l'emploi de vaccins contre l'influenza et les infections pneumococciques dans les établissements de soins prolongés.

MODÈLES : Une enquête transversale a été effectuée auprès d'un échantillon aléatoire de 30 établissements dans deux régions du Québec. L'information a été recueillie auprès du directeur général ou la directrice des soins infirmiers, auprès de tous les médecins appelés en consultation et d'un échantillon aléatoire de 20 résidents de chaque établissement.

voir page suivante

Département des Sciences de la santé communautaire, Université de Sherbrooke; Centre de Recherche en Gériatrie et Gérontologie, Hôpital d'Youville, Sherbrooke, Québec; Direction de la Santé publique, Régie de la santé et des services sociaux de la Montérégie, Québec; Direction de la Santé publique, Régie de la santé et des services sociaux de l'Estrie; Centre de Recherche Clinique du Centre Universitaire de Santé de l'Estrie, Québec

Correspondence and reprints: Dr Philippe De Wals, Département des Sciences de la santé communautaire, CUSE, 3001, 12ième Avenue-Nord, Sherbrooke, Québec J1H 5N4. Telephone 819-564-5348, fax 819-564-5397, e-mail pdewals@courrier.usherb.ca

Received for publication April 10, 1996. Accepted June 27, 1996 
RÉSULTATS : Vingt-neuf centres ont accepté de participer à l'enquête. Le taux de vaccination moyen contre l'influenza était de $70 \%$ et n'était pas influencé par les différences quant au type d'établissement ou quant à l'organisation des programmes d'immunisation. Le principal obstacle à la vaccination contre l'influenza signalé par les médecins était le refus d'une importante proportion de résidents. Parmi les résidents qui au départ n'avaient pas demandé de vaccin contre l'influenza, les deux tiers seulement ont accepté la vaccination lorsqu'elle leur a été offerte. La majorité des résidents se sont dits satisfaits des renseignements reçus et du respect manifesté envers leur liberté de choix. Quarante pour cent des résidents ont été jugés inaptes à fournir un consentement éclairé et le taux de vaccination a été de $76 \%$ auprès de ce groupe. Un tiers seulement des médecins ont obtenu sans problème l'autorisation d'un proche ou d'un tuteur avant de prescrire la vaccination à des résidents jugés inaptes. Aucun des établissements étudiés n'était doté de programme efficace de vaccination contre les infections pneumococciques. Quarante-trois pour cent seulement des médecins ont signalé l'emploi de tels vaccins; $98 \%$ des résidents n'en avaient jamais entendu parler.

CONCLUSIONS : L'objectif national d'une couverture à $95 \%$ au moyen du vaccin contre l'influenza sera difficile à atteindre dans les établissements de soins prolongés, surtout parce qu'une minorité de résidents ne risque pas d'être convaincus des avantages d'une telle immunisation. Il reste beaucoup à faire pour promouvoir et administrer les vaccins contre les infections pneumococciques dans ce contexte.

$\mathrm{I}_{\mathrm{p}}^{\mathrm{n}}$ nfluenza and Streptococcus pneumoniae infections are important causes of morbidity and mortality in long term care facilities. In a meta-analysis of 20 cohort studies, 19 of which involved institutionalized elderly patients, influenza vaccine efficacy was estimated at $53 \%$ for preventing pneumonia and $68 \%$ for preventing death (1). Results from a survey in nursing homes in Michigan indicated that a vaccination rate of residents of greater than $80 \%$ can reduce the frequency of influenza outbreaks (2). In Quebec, a provincial immunization program against influenza was established in 1975. Vaccines are purchased by the Ministry of Health and are distributed, on request, free of charge to private and public long term care facilities. The objective of the program is to vaccinate $80 \%$ of residents. A national objective of $95 \%$ coverage in this setting has recently been adopted at a consensus conference organized by Health Canada (3).

Results from randomized and observational studies in chronic care facilities indicate that pneumococcal polysaccharide vaccines are effective in reducing the risk of invasive infection and pneumonia (4). Both the National Advisory Committee on Immunization and the Canadian Task Force on the Periodic Health Examination recommend that all residents of long term care facilities should receive the pneumococcal vaccine $(4,5)$. There is no public health program for the promotion and administration of this vaccine in Quebec. Pneumococcal vaccine must be prescribed on an individual basis and purchased, either by the resident or the facility, at a cost ranging from $\$ 12$ in hospital pharmacies to $\$ 22$ in drugstores.

The first objective of the present study was to evaluate the use of influenza and pneumococcal vaccines in a representative sample of long term care facilities in Montérégie and Estrie, two regions in southern Quebec containing about 17\% of the population in the province. The second objective was to identify obstacles to vaccine use as perceived by the general managers or chiefs of nursing, by the consultant physicians and by the residents. Additional objectives were to investigate opinions about and procedures for informing patients about the benefits and risks of vaccines and for obtaining consent or the necessary authorization for persons unable to provide valid consent.

\section{METHODS}

Ninety-two long term care facilities (52 public and 40 private) with a total of 6914 beds were registered in the two regions. A random sample of 30 facilities was selected, stratifying for five geographical areas and public or private status. The research protocol was approved by the ethics committee of the Youville Hospital in Sherbrooke, Québec.

In September 1992, a letter presenting the objectives of the study was mailed to the general managers of these facilities. They were contacted two weeks later by telephone to request their participation in the study. Every participating centre was visited by a trained interviewer who asked the general manager or chief of nursing to complete a questionnaire dealing with the organization of the facility and activities for promoting and administering vaccines to residents. A list of consulting physicians was obtained for each institution. A questionnaire concerning opinions and practices about influenza and pneumococcal vaccines was mailed to these physicians. A second mailing was sent if no response was obtained within three weeks. A random sample of 20 residents in each facility was selected for interview. Demographic characteristics and vaccination status against influenza were obtained from attending nurses. The ability of selected residents to be interviewed was evaluted, and persons with problems such as deafness, mental confusion or memory loss were excluded. Eligible residents were invited to participate in the study and during an interview, a questionnaire was completed dealing with knowledge, attitudes and experience with influenza and pneumococcal diseases and vaccines.

Confidence limits of proportions were computed on the basis of an elementary random sample. In univariate analysis, proportions of vaccines in different groups were compared by the $\chi^{2}$ test. The determinants of vaccination coverage in individual centres were analyzed in a multiple covariance model, in which the number of beds was a continuous covariable and six other categorial variables were controlled. These variables included the region, public or private status, selection of physicians made by the centre or the resident, existence of a special program for promoting the vaccine, existence of special clinics for immunization and existence of a standing order for immunization. 


\section{RESULTS}

Management: Of the 30 long term care facilities selected, 29 agreed to participate (16 public and 13 private). General managers completed the questionnaire in 20 cases and chiefs of nursing in nine cases. The smallest facility had seven beds and the largest 315 beds (median of 55 beds).

A program for administration of influenza vaccine did exist in every facility, but the manager of one institution had recently been appointed and was unable to provide details. Specific and coordinated activities for the promotion of the influenza vaccine were present in only 16 facilities. A standing order giving nurses the responsibility to vaccinate eligible residents was reported in 10 centres. Vaccines were administered by nursing personnel (24 of 28), by consulting physicians (two of 28), by nursing personnel or physicians (one of 28 ) or by a visiting public health nurse (one of 28).

Twenty-five facilities provided accurate information on the proportion of residents who had received the influenza vaccine during the fall of 1991 . Overall, $70 \%$ of 1888 residents had been vaccinated ( $95 \% \mathrm{Cl} 68 \%$ to $72 \%$ ). The coverage in individual centres ranged from $33 \%$ to $100 \%$. Nine centres had rates over $80 \%$ and three of these centres had rates over $95 \%$. The vaccination rate was not significantly influenced by the size of the centre, its private or public status or by characteristics of the in-house immunization program. Among the 29 general managers and chiefs of nursing who participated, only 13 were aware of the existence of the pneumococcal vaccine and only one claimed that the use of this vaccine was actively promoted.

Consultant physicians: The names of 106 consultant physicians were provided by participating centres and 73 physicians returned the questionnaire. The median age of respondents was 42 years (range 27 to 81 years) and $81 \%$ were male. The majority of physicians $(68 \%)$ claimed to recommend the influenza vaccine to all residents, $27 \%$ recommended the vaccine only to residents with a high risk condition, and a minority (3\%) never recommended the vaccine. The obstacles to vaccination considered important or very important by physicians are listed in Table 1 . The only obstacle reported by a large number of physicians (44\%) was refusal to receive the vaccine.

For residents unable to provide valid consent, $65 \%$ of physicians administered the influenza vaccine without obtaining consent, $19 \%$ sought consent from a family member or legal guardian, and $6 \%$ did not give the vaccine.

Pneumococcal vaccine was routinely recommended to all residents by only $6 \%$ of physicians, while $37 \%$ recommended the vaccine for high risk residents. The remaining physicians (57\%) reported no use of this vaccine. From the consulting physicians' point of view, the three most important obstacles to the use of pneumococcal vaccine were limited knowledge, physician omission and the fact that one must pay for it (Table 1).

Residents: A total of 567 residents aged 30 to 106 years (median age 82) were selected for study. Influenza vaccination status was unknown in 21 residents due to recent arrival at the facility. Personnel at participating centres reported that $64 \%$ (349 of 546) of residents had received influenza vaccine in the
TABLE 1

Various obstacles to the immunization perceived as important or very important by physicians $(n=73)$

\begin{tabular}{lcc}
\hline Type of obstacle & $\begin{array}{c}\text { Percentage (\%) } \\
\text { Influenza vac- } \\
\text { cine }\end{array}$ & $\begin{array}{c}\text { Pneumococcal } \\
\text { vaccine }\end{array}$ \\
\hline $\begin{array}{l}\text { Disease not perceived } \\
\text { as important by patient }\end{array}$ & 9 & 9 \\
Vaccine not well known & NA & 56 \\
Poor availability of vaccine & 1 & 21 \\
High cost of vaccine & NA & 42 \\
Vaccine not offered & 12 & 78 \\
$\quad$ to residents & 13 & 9 \\
$\begin{array}{l}\text { Difficulty in obtaining } \\
\text { informed consent }\end{array}$ & & \\
Vaccination not accepted & 41 & 31 \\
$\quad$ by residents & & 3 \\
Fear of adverse reactions & 5 & \\
Doubts about vaccine & 2 & \\
effectiveness & & \\
\hline
\end{tabular}

NA Not asked

fall of 1991 . Mental confusion was present in $40 \%(n=228)$ of the residents studied and this subgroup had a significantly higher vaccination rate than those without mental confusion ( $76 \%$ versus $57 \%$; $P<0.0001)$. Nine per cent $(n=51)$ of residents had another medical problem and could not be interviewed.

Only $51 \%$ (288 of 567 ) of residents were judged to be capable of responding to the questionnaire. A large majority (87\%) of these 288 persons were well aware of the influenza vaccine ('flu shot'). Among these 251 residents, 22\% had actually asked to be vaccinated and $83 \%$ were offered the vaccine, either by a nurse ( $76 \%$ of cases) or a physician ( $24 \%$ of cases). When the influenza vaccine was offered, the benefits and risks of vaccination had been explained in $92 \%$ of cases. Of those receiving the information, $96 \%$ were satisfied and felt free to refuse to be vaccinated. Of the residents who did not ask to be vaccinated, $80 \%$ were offered vaccination and $64 \%$ of the latter accepted. The fact that the vaccine was offered by a nurse or a physician did not influence the vaccination rate.

Among the 251 residents aware of the influenza vaccine and able to respond to the questionnaire, 100 (40\%) had not been vaccinated in the fall of the year preceeding the study. Fear of needles, 'allergy' to the vaccine, a previous negative experience and lack of peer vaccination were not cited as important reasons for not being vaccination. The main reasons given for nonvaccination were the impressions that influenza is not a serious disease (24\%) and one has little chance of getting 'the flu' (33\%), doubts about the vaccine's effectiveness (38\%), and fear of side effects of vaccination (24\%).

When competent residents were asked about their wishes should they become unable to consent to vaccination, $72 \%$ wanted consent to be obtained from a family member or legal guardian, $18 \%$ wanted the decision to be made by a physician and $8 \%$ wanted nursing personnel to make the decision. The majority (81\%) felt that consent should be obtained each year, 
while $19 \%$ felt that a single consent could extend to subsequent years.

Pneumococcal vaccine was completely unknown to $98 \%$ (282 of 288) of the residents. None of the six residents interviewed who had heard about pneumococcal vaccine knew whether they had been vaccinated and none of them lived in a facility that allegedly had a program to promote this vaccine.

\section{DISCUSSION}

The influenza vaccination rate among residents in long term care facilities studied in the regions of Estrie and Montérégie was $70 \%$ in the 1991/1992 season. This is slightly higher than the provincial rate of $67 \%$, found by an independent survey conducted in 1990 and 1991 (6). Only one-third of these facilities reached the provincial objective of $80 \%$ coverage and one of 10 reached the national objective of $95 \%$ coverage.

Recently, a meta-analysis was performed to assess the effectiveness of influenza immunization delivery methods (7). System-oriented strategies were more effective than clientoriented or provider-oriented approaches. The former consisted mainly of standing orders. In the present study, neither the characteristics of the facilities nor the institutional immunization programs significantly influenced the level of coverage. However, the reduced size of the sample certainly limits the power of this study to detect effects of small magnitude. Our observation could also be explained by the existence of a program characteristic (eg, a standing order) that may not indicate the degree of its implementation or its quality. More precise methods of observation than those used in this study are needed to evaluate these factors.

The competence of residents in long term care facilities and how health care providers deal with incompetent individuals can have major impact on influenza vaccination coverage. Forty per cent of the residents selected for this study had mental confusion and another $10 \%$ were unable to complete a face to face interview for other medical reasons. One survey in Michigan showed that nursing homes requiring signed consent from relatives had lower influenza vaccination rates than homes without this requirement (8). Quebec has legislation requiring informed consent for immunization and a verbal or written authorization from a designated person or a relative for those who are unable to provide a valid consent (9). Authorization has to be sought each season because the composition of the influenza vaccine is modified (type of viral strains and industrial process) year after year, and the risk of adverse effects may vary between different vaccines (10). The majority of residents questioned in this study desired that third-party consent be obtained annually from a family member or legal guardian should they be unable to provide consent for influenza vaccination. Physicians' behaviour concerning mentally challenged persons was far from ideal. Only $29 \%$ of physicians delayed vaccination until the necessary authorization was obtained. The formulation and implementation of institutional policies in this area could help overcome this problem. Among residents in long term care facilities who were able to give valid consent, the vast major- ity reported that the information provided was adequate and that freedom of choice was respected.

Refusal to be vaccinated was identified as another major factor influencing influenza vaccine coverage. If residents who requested vaccine are excluded, only $64 \%$ of those offered the vaccine accepted. We do not know whether some types of face to face approaches were more effective than others in convincing residents, and there is no comparative trial on this. The reasons given for refusal in our study were consistent with a classic model of health beliefs, including perceived susceptibility to the disease, perceived seriousness of the disease, and perceived benefits and risks of taking action (11). A recent study among elderly persons in the United States revealed the existence of a 'hard core' of refusers, about $15 \%$, who were unlikely to be influenced by any education method (12). Such a hard core contributed to the relatively low rate of vaccination in the present study and probably explains why the effectiveness of interventions aimed at improving vaccine acceptance decreases when the background rate of vaccination is high (7). For this reason, it may be difficult to reach the national objective of $95 \%$ influenza vaccination in long term care facilities.

In the province of Quebec, approximately 4000 doses of pneumococcal vaccine are distributed each year, but there are no data available on the vaccination coverage in different population groups at increased risk of pneumococcal disease or its complications (4-5). Pneumococcal vaccine should be recommended for the majority of residents in long term care facilities. Although it was not possible to assess the exact vaccination rate, the results of the present study confirm the underuse of the vaccine in this setting. Much remains to be done to promote the appropriate use of the vaccine. As identified in this study, a reasonable place to start would be the education of physicians, health care facility managers and nursing personnel about the importance of pneumococcal diseases and the benefits of immunization. Eventually, full use of pneumococcal vaccine for residents of long term care facilities may require a provincial program offering the vaccine free of charge.

ACKNOWLEDGEMENTS: The study was supported by a grant from the Quebec Pulmonary Association. The authors thank Brian Ward and Lonny Erickson for help in writing the paper.

\section{REFERENCES}

1. Strassburg MA, Greenland S, Sorvillo F, et al. Influenza in the elderly: Report of an outbreak and a review of vaccine effectiveness reports. Vaccine 1986;4:38-44.

2. Patriarca PA, Weber JA, Parker RA, et al. Risk factor for outbreaks of influenza in nursing homes. Am J Epidemiol $1986 ; 124: 114-9$.

3. Canadian Consensus Conference on influenza. Can J Infect Dis 1993:4:251-6.

4. Canadian Task Force on the Periodic Health Examination. Periodic health examination, 1991 update: 2 . Administration of pneumococcal vaccine. Can Med Assoc J 1991;144:665-71.

5. Canadian Immunization Guide, 4th edn. Ottawa: Ministry of National Health and Welfare, 1993:92-4.

6. McArthur MA, Sirmor AE, Campbell B, McGeer A. Influenza and pneumococcal vaccination and tuberculin skin testing programs in long term care facilities: Where do we stand? Infect Control Hosp Epidemiol 1995;16:18-24.

7. Gyorkos TW, Tannenbaum TN, Abrahamowicz M, et al. Evaluation of the effectiveness of immunization delivery methods. Can J Public Health 1994;85(Suppl 1):14-30. 
8. Patriarca PA, Weber JA, Meissner MJ, et al. Use of influenza vaccine in nursing homes. J Am Geriatr Soc 1985;33:463-6.

9. Protocole d'immunisation du Ouébec. Ouébec: Ministère de la santé et des services sociaux, 1995:2.1-2.8.

10. Kilbourne ED. Influenza. New York: Plenum Medical Book Company, 1987:291-345.
11. Rosenstock IM. Why people use health services. Milbank Mem Fund Q 1966;44(Suppl 3):94-127.

12. Buffington J, LaForce M. Achievable influenza immunization rates in the elderly. NY State J Med 1991;91:433-5. 


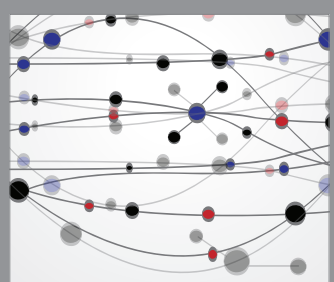

The Scientific World Journal
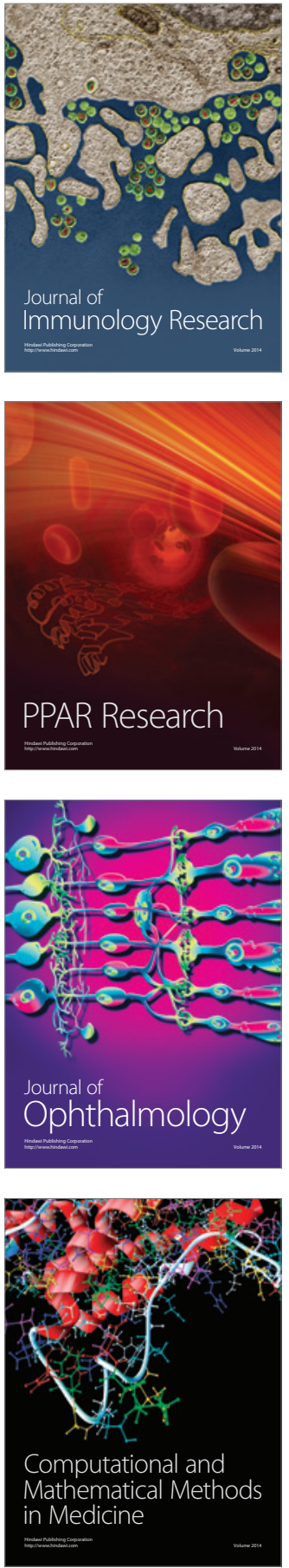

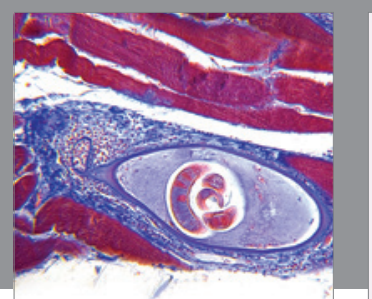

Gastroenterology Research and Practice

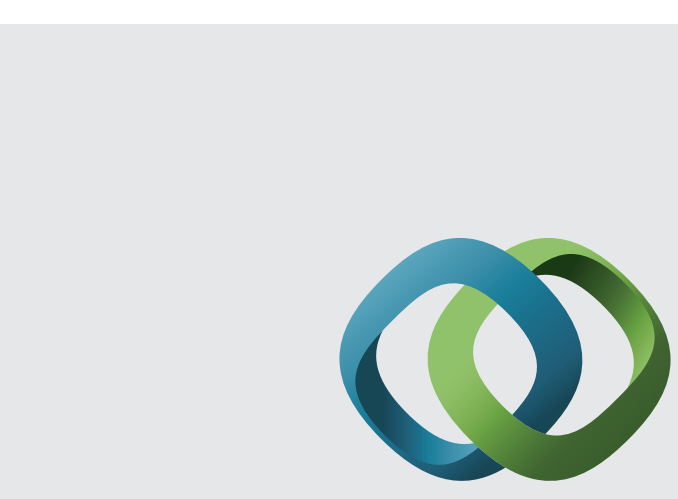

\section{Hindawi}

Submit your manuscripts at

http://www.hindawi.com
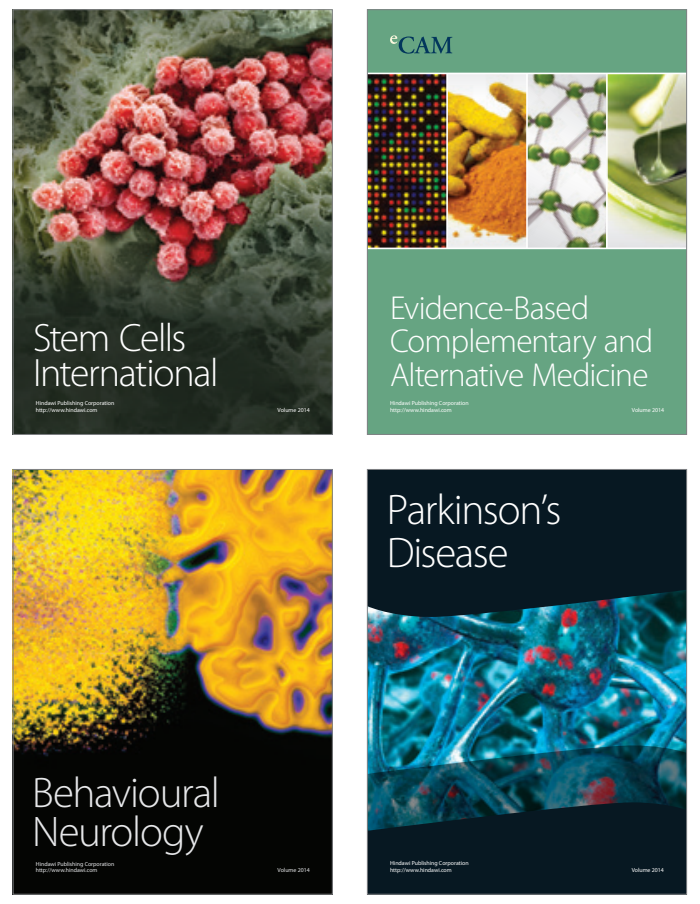
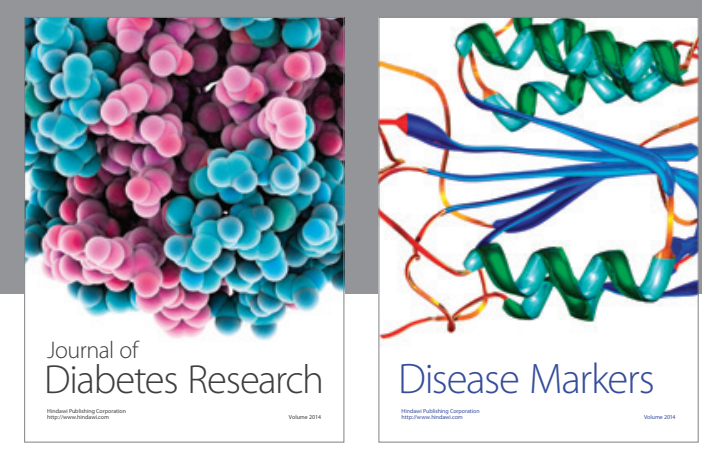

Disease Markers
